\title{
Afterlife Research and the Shamanic Turn
}

\author{
Michael Grosso, Ph.D. \\ New Jersey City University
}

\begin{abstract}
In Western culture, approaches to the afterlife have mutated throughout history, from shamanism and mythology to philosophy, spiritualism, and psychical research. For conceptual reasons, however, survival research seems to many to be languishing, despite some remarkable recent advances. I urge a return to a more experience-based approach, modeled after features of the near-death experience, for its practical benefits; I intend that approach to complement other forms of research, not displace them. Finally, I underscore the unique status of survival research as a scientific pursuit.
\end{abstract}

KEY WORDS: afterlife; shamanism; philosophy.

\section{The Twisty Road of Research}

Immortality is an ancient problem in philosophy. Philosophers since the days of Plato and Descartes used a priori arguments to deduce the soul's immortality, but beginning in the 19th century with philosopher Henry Sidgwick and classical scholar Frederic Myers, the immortality project changed in two ways. First, intuition and speculation were laid aside, and research became empirical; one looked at ghosts, apparitions, and mediumship for evidence of an afterlife. Secondly, one now spoke more modestly of survival instead of immortality. In tune with a more fallibilist modern outlook, people have lost faith in the power of pure reason to solve the riddles of the universe.

At most we hope that certain types of evidence will incline us to believe that some people in some way survive death. It has taken almost

Michael Grosso, Ph.D., is Chairman and Associate Professor of Philosophy and Religion at New Jersey City University. Reprint requests should be addressed to Dr. Grosso at 26 Little Brooklyn Road, Warwick, NY 10990; e-mail: mgrosso@warwick.net. 
the whole of human intellectual history to shift from a mythological and speculative approach to one that is data-based and experiencecentered. On the other hand, the shamanic roots of Greek philosophy were themselves experience-centered (Cornford, 1965, see especially pp. 62-106). The shaman, in traditional societies, is a master of altered states of consciousness, an empirical explorer of alternate realities. The shamanic origins of Greek philosophy may be seen in Plato's definition of philosophy as the "care of the soul" and the "practice of death," as well as in his definition of the philosopher as a "spectator of all time and existence."

I believe it is time for another shift in the approach to the problem of "immortality," and I recommend a return to a shamanic model of research. However, to distinguish this suggestion from reactionary naivete, let me speak of a postmodern shamanic model. As the approach of the early psychical researchers did not displace the earlier traditions but built upon their insights, so would the shamanic turn (or return) that I propose rest on existing empirical findings. Owing to the uniquely existential challenge of the afterlife question, I believe that the inquirer needs to participate more intimately in the research; the whole person must get involved, the emotional and intuitive side as well as the rational. This is a research question like no other; it touches on the most dramatic issues a human being can confront: one's ultimate nature, range of hope, possible experience, and spiritual destiny.

\section{The Superpsi Impasse}

Let us begin with three points about the evidence for life after death. First of all, such evidence exists-a fact that needs to be underscored. I say this because a few writers seem to think that it makes no sense to talk about evidence for life after death. The majority of researchers, however, have operated on the assumption that there are types of reported incidents that plausibly, and without self-contradiction, may best be explained by assuming that someone has survived death: for example, apparitions that reveal information unknown to any living person; memories, imaged and behavioral, that children have of other people's lives; or certain statements that issue from mediums about deceased people. Narratives of this sort exist in significant numbers; there is room to disagree about them, but postmortem survival is often at least an intelligible interpretation. 
The second point about the evidence is its epistemic indigestibility. Thanks to scientific materialism, the dominant metaphysical conceit of the age, anything supporting the reality of minds as substances-which survival would clearly imply-tends to be ignored, if not repressed, by the watchdogs of mainstream culture.

The third point brings us to the crux of the shamanic turn. The evidence for survival that researchers have been collecting and analyzing for well over a hundred years has led to a seeming impasse, thanks to certain curious problems of interpretation. Consider an often cited example: A man obtained information from a series of dreams of his father about a lost will. No living person knew of the whereabouts of this document. The case was probated, and the authenticity of the father's last will was confirmed (Richmond, 1938, pp. 28-31). This story admits of two interpretations: the intelligence that located the will came from a dead man, or the living son discovered the will by means of his clairvoyance. The young man was of course also motivated to find the will, which benefited him. Unfortunately, it is hard to interpret such cases; it always seems possible to see the evidence in a way that suits one's bias toward belief or disbelief in survival. It often depends on the slant one takes.

As the early researchers encountered the peculiar difficulties of their task, they looked for cases more difficult to account for by the paranormal or psi abilities of the living. Meanwhile, skeptics continued to refine the case for covert psi abilities of the living to account for the data. Consider a few examples: In the early days of mediumship, a sitter anxious to communicate with a deceased loved one sent a proxy to the medium. This would rule out the medium fishing for information from the mind of the proxy sitter, who knew nothing of the deceased target person. But it soon became evident that the paranormal outreach of great mental mediums like Eleanora Piper or Gladys Osborne Leonard was quite extensive, and investigators realized that mediums might obtain the necessary information from sources located anywhere.

Such presumed abilities are called superpsi because they exceed anything known in experimental parapsychology. The appeal of superpsi lies in its relative simplicity; it involves only an extension of known abilities of living people. By contrast, assuming life after death implies a radical extension of what is known to be empirically possible.

To sum up a long story, it turns out that the chief rival to the survival hypothesis is equally momentous: people possess uncanny paranormal abilities, through which they may obtain information from distant and multiple sources and produce the appearance of convincing phantasms 
of the living or the dead. Superpsi thus became the focal point of the afterlife enigma.

However, certain types of evidence have been singled out that seem to strain this hypothesis, including book tests, collectively perceived apparitions, drop-in communicators, cross-correspondence material, and other phenomena. All these suggest autonomous agency. For example, in cases of so-called "drop-in communicators," an intelligence that identifies itself as an unknown deceased person "drops in" on a medium's home circle and conveys its identity (later verified) and other correct facts about its personal history through the medium. This strains the superpsi explanation, which is tied to the concept of motivation. For, if the personality who drops in is unknown to any of the sitters or to the medium, where is the motivation to manifest coming from? It seems reasonable to suppose the intelligence is coming from outside the circle rather than from anyone within it. Suppose, moreover, as Alan Gauld (1982) has pointed out, that the information confirming the medium's statements comes from several sources: different physical records, minds of different living people. The absence of motivation (from medium or sitters) and the complexity of the sources weigh against the medium being the intelligence behind the "drop-in." It seems simpler to assume that the source was the dead person.

But arguments keep appearing that fend off puzzlers like drop-in communicators. Take the complexity-of-source problem just alluded to. Stephen Braude (1988, pp. 177-195) has reminded us that studies show psi operates independently of task complexity. According to Helmut Schmidt (1974), psi is a goal-oriented process. Just as the physical complexity of a psi task with a random event generator is no obstacle to success, neither should the complexity of sources be an obstacle to mediumistic scanning for needed data.

David Griffin (1997) offered an even simpler rejoinder to the dropin challenge. He suggested that a medium could obtain all the needed information about the personality who seemed to be dropping in by retrocognizing the mind of the dead person when he or she was alive. Experimental evidence for retrocognition is hard to come by; however, if we accept precognition (which Griffin does not, by the way), why not entertain the possibility of retrocognition?

Psi, like all mental functions, is motivated. We cannot invoke superpsi automatically, as some might be tempted to do, to explain away evidence; we have to show the presence of a motivated agent. So where is the motivation at a seance with a drop-in communicator? No particular motive of anyone present at the seance seems plausible. But I 
think it possible to invoke a general motive, as it were, a disposition, an automatic tendency to generate images and associations suggestive of survival or immortality.

Several kinds of data suggest we may be so disposed to manufacture simulations of immortality. Anita Muhl (1930), in her study of automatic writing, found that graphic automatisms regularly involve narratives of spirits, elves, fairies, and daemons. That is, once the writer enters the "automatic zone," fantastic otherworldly narratives spontaneously show up. Mythology, of course, which partly originates from this automatic zone, is rife with images of otherworlds. Again, in our dreams, we regularly produce hallucinations of recognizable, deceased people. In addition, phenomena of dissociation and multiple personality involve the creation of new and sometimes distinctly different and even more complex personalities.

Sometimes these automatic simulations of survival and otherworldliness appear in mediumship. Consider two well known cases: In one, an investigator asks a medium to contact a certain Bessie Beals, said to have passed over. Before long, a personality starts to come through who calls herself Bessie Beals. The problem is that the investigator was testing the medium; there was no Bessie Beals. Nevertheless, in response to suggestive prompting, the medium automatically impersonated a nonexistent spirit (Murphy, 1945, pp. 75-76).

The next example further complicates the story. Add to the "automatic zone" a sizeable portion of paranormal capacity, and you get the highly misleading performance of the medium Blanche Cooper, who conveyed accurate information to $\mathrm{S}$. G. Soal about an old friend of his, Gordon Davis, whom Soal mistakenly thought had died in the First World War. As a result of the medium's performance, Soal was led to believe his old school chum had survived death. The one hitch was that Davis was alive and well. The medium had picked up accurate information about a distant person she had never met, and unconsciously created the illusion that a dead man was communicating with the living (Soal, 1926). In this case, the imposture was exposed. One wonders how many seemingly authentic cases of survival are paranormal impostures.

One argument against superpsi is that it is not based on laboratory findings. On the other hand, why believe that the limits of psi are defined by the findings of experimental parapsychology? Most experimental set-ups are not very exciting or meaningful, and the effects they generate are typically marginal. The big effects arise in emotionally charged and meaningful contexts. If we add to the equation "miracles" and siddhis of mystics and shamans, as well as materialization, 
levitation, teleportation, and sundry auditory and photic effects of mediums like Eusapia Palladino and D. D. Home, we can begin to see what a huge repertoire of potential abilities for simulating survival may be available.

In the end, only a case-by-case analysis can give reliable answers. As things stand, some have concluded in favor of survival; but not all who have studied the data have been convinced. One is always free to play up or play down particular facts or slants on facts, and thus favor one interpretation or the other. True, the crucial experiment will come eventually for us all; but in the meantime, given our hopes and fears, it is hard to be sure whether we have been swept along by personal bias. And of course, bias can work against the afterlife hypothesis as well as for it (Grosso, 1992, pp. 81-93).

\section{Beyond the Superpsi Antinomy}

For researchers like J. B. Rhine, superpsi lands us in a kind of Kantian antinomy: For every attempt to interpret a piece of evidence in support of survival, it always seems possible, if one is ingenious and persistent enough, to devise a counterargument. Let us suppose we are at such an impasse or "antinomy." What is the next move?

We come now to my proposal of taking the shamanic turn. In effect, this means the return to the experiential, phenomenological, and pragmatic roots of belief in otherworlds, spiritual beings, and afterlives. The general idea behind the mutation of survival research I am urging is this: We might advance our understanding if we succeeded in gaining an inside perspective on what postmortem states might be like or feel like.

We owe it to our selves to be more adventurous in these explorations. So far, survival research has been trace-oriented. One studies "traces," indications that some other person has survived death: a trace could be an apparition that seems to originate from an excarnate personality; a mediumistic deliverance that points to minds that have survived death; or memories, physical marks, or behaviors that imply reincarnation of a previous personality. This is empirical research based on inferences. The investigator tries to authenticate a story and then determines if survival is the best explanation. This inferential procedure, made up of many interlocking steps, is based on sources that are objective and publicly observable.

There is, however, a kind of survival-related evidence that works differently. In the near-death experience, the source of evidence is 
subjective and immediate; the experiencer claims to know there is a life after death. This type of evidence involves "knowing" as direct awareness, unmediated revelation, and nonlinear intuition. No deductions from reports, no critically-filtered observations, but rocket-fast entry into the dead zone. "Proof" arises by means of a dramatic alteration of one's state of mind. Near-death experiencers, like shamans, seem to themselves to enter another world, another mode of consciousness.

Of course, to the outside observer, the claims of the near-death experiencer need carry little weight. At most, certain features of the experience such as reports of verifiable out-of-body experiences (OBEs) suggest survival (Cook, Greyson, and Stevenson, 1998, pp. 377-405). Nevertheless, near-death experiences (NDEs) do provide a model, a paradigm for a more direct exploration of possible other worlds. In line with the terminology of Joel Schumacher's 1990 movie, let us call this the Flatliner paradigm; in this movie, medical students, unhappy about the failure of religion and philosophy to solve the great mysteries, decided to use their scientific expertise to induce temporary death, and to peek at what may lie on the "other side." Needless to say, I am not recommending such reckless experimentation. By the Flatliner paradigm I mean something already familiar to traditional spiritual practice.

In fact, individual experimenters (perhaps explorers is the better word) could try to replicate three components of the NDE. The first is the out-of-body experience. Enough hints in the literature suggest ways in which we might learn to induce the out-of-body experience in ourselves; in fact, there are all sorts of techniques available for triggering them (Rogo, 1983). The more we managed to induce OBEs in ourselves, the more we might learn about the limits of consciousness, whether we are geniuses at self-deception or immortal spirits caged in mortal bodies. It would be interesting to observe the effects of frequent OBEs on our belief systems and lifestyles, whether, for example, it would reduce death anxiety and free up our psychic energies for the business of living.

The second often reported NDE component we could try to replicate is seeing apparitions of loved ones. Raymond Moody (1992) has resurrected an ancient mirror-gazing technique he calls a psychomanteum, whose purpose is to stimulate apparitions of deceased loved ones, a procedure, as used by Moody, meant primarily to assist bereaved patients. Moody's work calls attention to the therapeutic side of survival research, which is an important aspect of the shamanic turn.

There is another aspect of the NDE that could be the basis of a new form of experimentation: the light experience. One of the most 
powerful and widely reported aspects of the near-death experience is the encounter with an overwhelming presence of light that seems to emanate pure love and that results in the utter conviction of the reality of the other world. A superb example of this may be found in Joseph McMoneagle's Mind Trek (1993, pp. 27-34). Based on my own experience of encountering the light in a dream (Grosso, 1997), and the study of an extensive literature, I am convinced it is possible to induce transcendent light experiences.

First, as researcher and pediatrician Melvin Morse (1992) has stressed, experiencing the light is the most deeply transformative aspect of the NDE; it reduces the fear of death and produces confidence and conviction of the reality of another world. No amount of critical examination of externally derived data could produce such an impact. Second, the near-death light is part of a universal pattern of human experience, an archetypal constellation of psychic constants, found everywhere in shamanic, mystical, esthetic, and inspired states of being (see, for example, Eliade, 1965, pp. 19-77).

Third, Chinese, Tibetan, and Sufi traditions describe techniques for inducing these mystic light encounters. They consist of related practices such as meditation, regulated breathing, visualization, conscious dreaming, diet, sensory isolation, and so forth, which can be adapted to researchers' needs. The appeal of this type of experiment is not just that it may afford us a glimpse of what may be another world, but that it may serve as part of a deep process of self-transformation.

Let me conclude with these remarks. I recommend the shamanic turn not as a substitute for inferential research but as a therapeutic, experiential complement. After all, death is not just another scientific or philosophical puzzle; it underlies the consciousness of our whole existence. On pragmatic grounds we need a working hypothesis for coping with our mortality. As Carl Jung (1979, p. 213) put it, we should do our best to "form a conception of life after death, or to create some image of it. . . Not to have done so is a vital loss."

Subjective experiences, however stunning, will never prove survival, and we may never know for sure if there is a life after death. On the other hand, in the course of our subjective encroachments on the presumptive "next" world, the likelihood increases that we will encounter new data and gain new insights. In time, a new consensus on the afterlife might conceivably emerge and change our whole feeling about death. From a practical point of view, is that not what counts?

The kind of research I am lobbying for promises less to solve than to dissolve the discomfiting uncertainty we associate with death; in the 
end, we may arrive at a place where the question of personal survival just does not matter any more. There are experiences in which the importance of the "I" seems to thaw, melt, and fade away into a vaster frame of reference. These experiences, often called transpersonal, combined with the best survival data, offer the raw materials for a 21st century ars moriendi, an art of dying.

I began by talking about how the classical philosophers approached the afterlife. They did so using general abstract principles (the soul is a simple substance, therefore it cannot die), a method totally out of tune with our modern empirical approach. At the same time, there was an experiential background to Greek philosophy, as Francis Cornford (1965) explained. Behind the tradition of Plato, Aristotle, and Plotinus was an older tradition of shamanic thinkers like Empedocles, Epimenides, and other sages of the ancient school.

The ecstatic experience was at the root of Greek philosophy; even Greek skepticism was a form of consciousness alteration, an attempt to achieve a state of awareness beyond all conflicting positions, ataraxiaa kind of floating indifference. In the Phaedo, Plato defined philosophy as the practice, the rehearsal for death. According to Socrates, only when we shed our bodies will the truth be known.

There is a practical dimension to Plato's writings that blends with survival research. The main point of this paper is to call attention to the need for a personal form of experimentation, something like what Hindus calls sadhana or spiritual practice. So, when Plato wrote that philosophy is the practice of death (melete thanatou), he was saying that we can practice for our death by practicing detachment from material existence. Now the curious thing about the near-death experience is that it forces one to experience this detachment, suddenly and without preparation. Think of it as a speed course in Plato's metaphysics.

There is one more point of contact between Plato's concept of philosophy and the near-death experience: Both seem to agree on the final test, the benchmark for passing the course. Like the celebrants of the Eleusinian Mysteries, near-death visionaries must see the light, not just figuratively but the ineffable blaze itself. Thus, philosophy, in one stroke, recaptures its ancient goal of enlightenment. With our neardeath data, the hidden meaning of Plato's perennial metaphysics is revealed. In a famous letter, Plato (1966) described the moment of philosophical enlightenment as an experience of a brilliant light. Near-death epistemology, like Plato's, admits the validity of intuition, the value of mystic illumination. At the same time, we keep the empirical gains of the scientific method, which was the hope of the founders of psychical 
research. We borrow back from philosophy its practical shamanic dimensions, its readiness to explore the full range of consciousness, and not to be imposed upon by the prevailing views of reality and rationality. We reconnect with the shamanic origins of Western philosophy. The circle from experience to theory and back to experience would be complete.

\section{References}

Braude, S. (1988). Mediumship and multiple personality. Journal of the Society for Psychical Research, 55, 177-195.

Cook, E. W., Greyson, B., and Stevenson, B. (1998). Do any near-death experiences provide evidence for the survival of human personality after death? Relevant features and illustrative case reports. Journal of Scientific Exploration, 12, 377-406.

Cornford, F. M. (1965). Principium sapientiae:A study of the origins of Greek philosophical thought. New York, NY: Harper Torchbooks.

Eliade, M. (1965). The two and the one. New York, NY: Harper Torchbooks.

Gauld, A. (1982). Mediumship and survival. London, England: Heinemann.

Griffin, D. R. (1997). Parapsychology, philosophy, and spirituality. Albany, NY: State University of New York Press.

Grosso, M. (1992). Frontiers of the soul. Wheaton, IL: Quest Books.

Grosso, M. (1997). Soulmaking. Norfolk, VA: Hampton Roads.

Jung, C. G. (1979). Word and image. Princeton, NJ: Princeton University Press.

McMoneagle, J. ( 1993). Mind trek. Norfolk, VA: Hampton Roads.

Moody, R. (1992). Family reunions: Visionary encounters with the departed in a modernday psychomanteum. Journal of Near-Death Studies, 11, 83-120.

Morse, M., and Perry P. (1992). Transformed by the light: The powerful effects of near-death experiences on people's lives. New York, NY: Villard.

Muhl, A. (1930). Automatic writing. New York, NY: Helix Press.

Murphy, G. (1945). Three papers on the survival problem. New York, NY: American Society for Psychical Research.

Plato. (1966). Seventh epistle. In Collected dialogues (Hamilton, E., and Cairns, H., Eds.) (pp. 1575-1598). New York, NY: Random House.

Richmond, Z. (1938). Evidence of purpose. London, England: Bell and Sons.

Rogo, D. S. (1983). Leaving the body. Englewood Cliffs, NJ: Prentice-Hall.

Schmidt, H. (1974). Psychokinesis. In Mitchell, E. D. \& White, J. (Eds.), Psychic exploration: A challenge for science (pp. 179-193). New York, NY: Putnam.

Schumacher, J. (Dir.) (1990). Flatliners [Film]. Hollywood, CA: Columbia.

Soal, S. G. (1926). A report on some communications received through Mrs. Blanche Cooper. Proceedings of the Society for Psychical Research, 35, 471-594. 